\title{
Isolation and Partial Characterization of Some New Bacteriophages Active Against Asticcacaulis Strains
}

\author{
CAROL A. MIDDLETON AND J. L. PATE \\ Department of Bacteriology, University of Wisconsin, Madison, Wisconsin 53706
}

\begin{abstract}
The isolation and properties of 42 phages active against Asticcacaulis strains $\mathrm{AC} 2, \mathrm{C} 19, \mathrm{AC} 12, \mathrm{AC} 48, \mathrm{~S}-1, \mathrm{~S}-3$, and KA4A are described. The phages are divided into 12 groups according to host range and serology. Phages in groups I through IX are lytic for strain AC48 but not for AC2 or C19; those in groups I through VIII are also lytic for strains S-1 and S-3. Phages in groups X through XII are lytic only for strains AC2 and C19. Six Caulobacter strains are sensitive to one or more of these phages. The phages have no activity on strains of the 54 bacterial species, other than caulobacters, tested. Taxonomic implications are discussed. Mitomycin $\mathrm{C}$ treatment of the Asticcacaulis strains failed to induce any temperate phages but did induce three lytic activities.
\end{abstract}

Asticcacaulis and Caulobacter are members of the family Caulobacteraceae, which comprises gram-negative, unicellular, prosthecate bacteria that multiply by transverse binary fission $(7,13)$. These organisms undergo a dimorphic life cycle, during which a nonmotile prosthecate cell with a secreted holdfast divides to give rise to a motile, flagellated cell. The motile cell produces a holdfast, loses the flagellum, and differentiates a prostheca to complete the cycle. Known strains of Asticcacaulis have a rod-shaped cell with either subpolar prostheca and flagellum or with two lateral prosthecae and a polar flagellum $(12,13)$. Holdfast material is produced at or near the pole of the Asticcacaulis cell at a site different from that at which prosthecae develop.

Although numerous phages have been isolated which are lytic for species of Caulobacter (14; Szeyko and Gerencser, Bacteriol. Proc., 1967), only five phages have been isolated for Asticcacaulis. Of these five, $\phi$ Ac20, 21, and 22 are identical according to their host range and antiserum neutralization characteristics, and $\phi$ Ac24 and 25 are similar if not identical (14; J. M. Schmidt, personal communication). Temperate phages have also been demonstrated in Caulobacter strains (6), but they have not been seen in Asticcacaulis $(6,14)$.

Caulobacter phages have been used as a source of messenger ribonucleic acid (11), to mediate gene transfer (J. M. Schmidt and B. Ely, personal communications), to clarify the taxonomy of caulobacters (13, 14; Szeyko and Gerencser, Bacteriol. Proc., 1967), to isolate phage-resistant mutants for genetic studies (9, 10 ), and to assay morphogenesis in synchronous populations of caulobacters $(3,8,15-17)$.
The present report deals with the isolation and partial characterization of bacteriophages capable of infecting various strains of Asticcacaulis. This study started as an attempt to isolate a viral system capable of mediating gene transfer in Asticcacaulis and to further elucidate the relationship between members of the family Caulobacteraceae as well as between caulobacters and members of other families of bacteria.

\section{MATERIALS AND METHODS}

Media. The standard complex PYE medium of Poindexter (13) was used for cultivation of Caulobacter and Asticcacaulis strains. Isolation and propagation of phages were carried out in PYE containing $0.1 \% \quad \mathrm{MgSO}_{4} \cdot 7 \mathrm{H}_{2} \mathrm{O}$. Nutrient broth (Difco), TYeG, or $0.5 \%$ peptone (Difco) in distilled water was used to propagate other bacterial species used in the host range study. The TYeG medium consisted of $1 \%$ tryptone (Difco), $0.3 \%$ yeast extract (Difco), and $0.5 \%$ glucose in distilled water. The plating medium contained $1.5 \%$ agar, and soft-agar overlays contained $0.7 \%$ agar. Each plate contained $30 \mathrm{ml}$ of bottom PYE agar.

Bacterial strains. All Caulobacter strains as well as Asticcacaulis strains AC2, AC12, AC48, S-1, and KA4A were obtained from Jean M. Schmidt of Arizona State University. The designations of these strains are according to Poindexter (13). A . biprosthecum C19 (= ATCC 27554) and Asticcacaulis S-3 were obtained from our laboratory's culture collection. Strains of the following species were also studied: 11 species of Bacillus, Escherichia coli (3 strains), Salmonella enteritidis, Citrobacter freundii, 3 species of Enterobacter, Serratia liquefaciens, Serratia marcescens, Pectobacterium caratovorum, Proteus vulgaris, Providencia alcalifaciens, 4 species of Micrococcus, Staphylococcus aureus, Staphylococcus epidermidis, Acetobacter aceti, Acetobacter suboxydans, Agrobacterium radiobacter, Agrobacter- 
ium tumefaciens, Acinetobacter calcoaceticus, Alcaligenes faecalis, Arthrobacter crystallopoietes, Azotobacter vinelandii, Brevibacterium linens, Chromobacterium lividum, Propionibacterium shermanii, Pseudomonas aeruginosa, Pseudomonas fluorescens, Zooglea ramigera, 5 species of Lactobacillus, Leuconostoc mesenteroides, Streptococcus faecalis, Streptococcus lactis, Mycobacterium smegmatis, Nocardia corallina, Streptomyces mediterranei, and Sphaerotilus sp. All cultures of these strains were obtained from the University of Wisconsin Department of Bacteriology culture collection.

Isolation of bacteriophages. The enrichment and isolation techniques of Schmidt and Stanier (14) were used for the isolation of bacteriophages from sewage and lake water. This procedure was modified in isolating phages for the slow-growing $A$. biprosthecum. Samples were filtered with a sterile, 0.45$\mu \mathrm{m}$ membrane filter (Millipore Corp.) to eliminate competing bacteria and were added to equal volumes of double-strength broth cultures of $A$. biprosthecum. These enrichments were incubated with slow shaking for $24 \mathrm{~h}$ at $30 \mathrm{C}$, were again filtered, and were then spotted on overlayers containing the bacterial host. Plates were examined for plaques after 2 and 5 days of incubation at $30 \mathrm{C}$.

Phage assays were carried out by the agar layer method of Adams (1) using $2 \mathrm{ml}$ of PYE agar, 0.1 to $1.0 \mathrm{ml}$ of phage, and 0.2 to $0.4 \mathrm{ml}$ of an exponentially growing culture of an Asticcacaulis strain. The amount of the bacterial inoculum depended on the turbidity of the cultures and was increased to $0.5 \mathrm{ml}$ for $A$. biprosthecum. Plates were incubated at $30 \mathrm{C}$ for 5 days.

Preparation of lysates. Phage stocks were prepared by eluting agar overlayer plates giving confluent lysis. Up to 105 -min elutions were made with $1.5 \mathrm{ml}$ of PYE broth per plate for each elution. These lysates were filtered or poured over chloroform and stored at $4 \mathrm{C}$ in screw-capped tubes. Titers of $10^{7}$ to $10^{11}$ plaque-forming units (PFU) per $\mathrm{ml}$ were obtained by this method.

Host range determinations. The host range of each phage was determined by spotting a lysate containing $10^{7}$ to $10^{10} \mathrm{PFU}$ on agar overlayers of the bacterial strains to be tested. Each plate was spotted with 4 to 10 lysates according to a grid drawn on the bottom of the plate. Plates were incubated at $30 \mathrm{C}$ and were examined for clearing of the lawn after 3 to 5 days for caulobacters and after $24 \mathrm{~h}$ for all other organisms. In most cases, no attempts were made to determine whether secondary propagations could be made from primary cleared areas. Thus, the host range that we report might, in some cases, indicate only that the host is sensitive to the phage but does not allow the phage to propagate.

Electron microscopy. Filtered phage lysates were concentrated by ultracentrifugation for electron microscope examination. The lysates were centrifuged for $1 \mathrm{~h}$ at $100,000 \times g$ ( 5 to $15 \mathrm{C}$ ) in a Beckman L2-65b ultracentrifuge with a Ti50 rotor head. Pellets were left in the centrifuge tubes overnight at $4 \mathrm{C}$ with 0.2 $\mathrm{ml}$ of buffer for slow resuspension.

These phage suspensions were negatively stained with $2 \%$ uranyl acetate or with $1 \%$ potassium phos- photungstate (pH 6.9) plus $0.005 \%$ bovine serum albumin (KPT-BSA) (4). Suspensions were placed on 200-mesh copper grids with carbon-coated Parlodion films and were stained for $5 \mathrm{~s}$ with freshly filtered stain. Specimens were observed with a Zeiss EM9S-2 microscope operated at $60 \mathrm{kV}$.

Attempted induction of temperate phages. Two methods were used in an attempt to induce possible temperate phages from all Asticcacaulis strains. For the broth method (6), mitomycin C (Sigma Chemical Co., St. Louis) was added to exponential-phase $A s$ ticcacaulis cultures to give a final concentration of $1.0 \mu \mathrm{g} / \mathrm{ml}$. Cultures were incubated for $15 \mathrm{~min}$ at $30 \mathrm{C}$ on a rotary shaker. The bacteria were sedimented, suspended in PYE, and incubated for $24 \mathrm{~h}$ at $30 \mathrm{C}$. These cultures were filtered, and the filtrates were spotted on all Asticcacaulis lawns. Plates were observed after 3 days of incubation at $30 \mathrm{C}$ for formation of plaques.

The rapid plate method was performed as described by Siddiqui et al. (18). All Asticcacaulis cultures were spotted onto PYE plates containing 0.01 , 0.1 , or $1.0 \mu \mathrm{g}$ of mitomycin $\mathrm{C}$ per $\mathrm{ml}$. Plaques seen within the spots were picked with sterile toothpicks and stabbed to fresh Asticcacaulis lawns.

Antiserum preparation and neutralization tests. Two phages were chosen as immunizing antigens, each phage representing a unique host range. Phage stocks containing at least $10^{10} \mathrm{PFU} / \mathrm{ml}$ in PYE were used to immunize female albino rabbits.

One week after the first intraperitoneal injection of $1.0 \mathrm{ml}$ of phage suspension, twice weekly intravenous injections were made for 3 weeks, starting with $0.5 \mathrm{ml}$ and increasing to $1.5 \mathrm{ml}$ by week 3 . After test bleeding from the marginal ear vein to determine the titers of neutralizing antibody, the rabbits were bled by cardiac puncture, and the sera were stored at $-25 \mathrm{C}$.

Neutralization tests were performed as described by Adams (1), except that the stocks used had a titer of $3 \times 10^{6} \mathrm{PFU} / \mathrm{ml}$ instead of $10^{7} \mathrm{PFU} / \mathrm{ml}$ and incubation was at $30 \mathrm{C}$.

\section{RESULTS}

Isolation of bacteriophages. A total of 42 phages were isolated against four Asticcacaulis strains. Table 1 shows the origin of each phage. Only 25 samples of source material had to be tested to obtain phages for Asticcacaulis strains S-1, S-3, and AC48, but more than 300 sewage and lake samples had to be screened before phages active against strain C19 were found.

Host range determinations. Based on host range and serology, the 42 Asticcacaulis phages fall into 12 groups. Table 2 shows the susceptibilities of Asticcacaulis strains to these phage groups. The first nine groups are lytic for strain AC48, and all but group IX are also lytic for S-1 and S-3, but none are lytic for A. biprosthecum $\mathrm{AC} 2$ or $\mathrm{C} 19$. The last three groups are lytic only for A. biprosthecum $\mathrm{AC} 2$ or $\mathrm{C} 19$. 
TABLE 1. Sources and original hosts of Asticcacaulis phages studied

\begin{tabular}{|c|c|c|}
\hline Asticcacaulis phages & $\begin{array}{c}\text { Original } \\
\text { host (Astic- } \\
\text { cacaulis } \\
\text { strains) }\end{array}$ & Source $^{a}$ \\
\hline$\phi \operatorname{Ac} 11,12$ & S-3 & Raw sewage no. 1 \\
\hline$\phi \mathrm{Ac13}$ & S-3 & Raw sewage no. 2 \\
\hline$\phi$ Ac14 & S-3 & Raw sewage no. 3 \\
\hline$\phi \operatorname{Ac15}$ & S-3 & Raw sewage no. 4 \\
\hline$\phi \operatorname{Ac} 31$ & S-3 & Raw sewage no. 5 \\
\hline$\phi \operatorname{Ac} 37$ & S-1 & Raw sewage no. 5 \\
\hline$\phi$ Ac39 & $\mathrm{AC} 48$ & Raw sewage no. 5 \\
\hline$\phi \mathrm{Ac} 33,38$ & S-3 & Raw sewage no. 6 \\
\hline$\phi \mathrm{Ac} 35,36$ & $\mathrm{AC} 48$ & Raw sewage no. 6 \\
\hline$\phi \mathrm{Ac} 41,42,45,46$ & $\mathrm{AC} 48$ & Pooled lake water and sewage \\
\hline$\phi$ Ac57 & $\mathrm{AC} 48$ & Raw sewage no. 7 \\
\hline$\phi \operatorname{Ac5} 9$ & AC48 & Raw sewage no. 8 \\
\hline $\begin{array}{l}\phi \mathrm{AcS}_{1}, \mathrm{~S}_{2}, \mathrm{~S}_{3}, \mathrm{~S}_{4}, \mathrm{M}_{1}, \mathrm{M}_{2}, \mathrm{M}_{3}, \mathrm{M}_{4}, \mathrm{M}_{5}, \mathrm{ML}_{1}, \mathrm{ML}_{2}, \mathrm{ML}_{3} \text {, } \\
\quad \mathrm{ML}_{4}, \mathrm{ML}_{5}, \mathrm{ML}_{6}\end{array}$ & C19 & Creek water \\
\hline$\phi \mathrm{AcS}_{5}, \mathrm{~S}_{6}, \mathrm{~S}_{7}, \mathrm{ML}_{7}, \mathrm{ML}_{8}, \mathrm{ML}_{9}, \mathrm{ML}_{10}, \mathrm{ML}_{11}, \mathrm{~J}_{1}$ & C19 & Lake water \\
\hline
\end{tabular}

${ }^{a}$ The source of raw-sewage samples 1 through 8 was a direct tap into the Madison sewer lines. Sample 1 was taken on 30 March 1973; 2, on 5 April 1973; 3, on 9 April 1973; 4, on 16 April 1973; 5, on 20 July 1974; 6, on 24 July 1974; 7, on 28 October 1974; and 8, on 7 November 1974. The pooled lake water and sewage came from lakes and ponds in Madison, from Madison sewage, and septic-tank sewage from sources near Madison. The creek water was from Willow Creek, and the lake water from the University Bay of Lake Mendota in Madison.

TABLE 2. Host ranges of phages on Asticcacaulis and Caulobacter strains ${ }^{a}$

\begin{tabular}{|c|c|c|c|c|c|c|c|c|c|}
\hline \multirow[b]{2}{*}{ Phage groups } & \multicolumn{6}{|c|}{ Asticcacaulis strains } & \multicolumn{3}{|c|}{ Caulobacter strains } \\
\hline & $\mathrm{AC} 2$ & C19 & $\mathrm{AC} 12$ & $\mathrm{AC} 48$ & S-1, S-3 & KA4A & CB8 & $\begin{array}{l}\text { CB9b, } \\
\text { CB24, } \\
\text { CB27, } \\
\text { CB28b }\end{array}$ & CB26b \\
\hline I. $\phi$ Ac11, 14 & - & - & - & + & + & - & - & - & - \\
\hline II. $\phi \operatorname{Ac} 12,13,15$ & $\mathrm{i}$ & $\mathrm{i}$ & - & + & + & i & + & - & - \\
\hline III. $\phi A \mathrm{Ac} 31,33,38,39$ & i & i & $\mathrm{i}$ & + & + & $\mathrm{i}$ & + & - & i \\
\hline IV. $\phi \mathrm{Ac} 35,36$ & i & $\mathrm{i}$ & $\mathrm{i}$ & + & + & $\mathrm{i}$ & - & - & - \\
\hline V. $\phi \mathrm{Ac} 37$ & i & $\mathrm{i}$ & $\mathrm{i}$ & + & + & i & - & - & $\mathrm{i}$ \\
\hline VI. $\phi A c 41,42$ & $\mathrm{i}$ & - & - & + & + & $\mathrm{i}$ & + & + & + \\
\hline VII. $\phi$ Ac 45,46 & - & - & - & + & + & - & - & - & - \\
\hline VIII. $\phi \operatorname{Ac5} 7$ & i & $\mathrm{i}$ & - & + & + & i & + & - & - \\
\hline IX. $\phi$ Ac59 & $\mathrm{i}$ & - & - & + & - & - & - & - & - \\
\hline X. $\phi \mathrm{AcM}_{2}, \mathrm{M}_{3}, \mathbf{M}_{4}, \mathrm{M}_{5}$ & + & + & - & - & - & - & - & - & - \\
\hline XI. $\phi \mathrm{AcS}_{1}$ & + & + & $\mathrm{i}$ & - & $\mathrm{i}$ & - & - & - & - \\
\hline XII. Other C19 phages & + & + & - & - & - & - & - & - & - \\
\hline
\end{tabular}

${ }^{a}+$, Clearing of the lawn; - , no clearing; i, faint clearing, appears to inhibit growth but not to cause cell lysis.

The following strains of Caulobacter were tested for susceptibility to the phages: $C$. fusiformis CB27 and CB29; type II strains CB24 and CB26b; C. henricii CB4, CBR, and CB23b; C. bacteroides CB7, CB8, CB9b, CB10b, CB11, and $\mathrm{CB} 11 \mathrm{a} ; C$. vibrioides subsp. limonus CB16b; C. variabilis $\mathrm{CB} 17 \mathrm{~b}$; type $\mathrm{V}$ strain CB28b; $C$. intermedius CB63; C. crescentus CB1, CB2, KA3, CB13b1a, and CB15; C. subvibrioides CB81; C. subvibrioides subsp. albus CB88 and CB89; C. leidyi CB37; C. vibrioides CBG, CB18a1, and CB51; as well as CB104, CB115, and CB111E, which have been isolated but not yet characterized by J. S. Poindexter.

Of these Caulobacter strains, only six gave positive results with any of the Asticcacaulis phages (Table 2). Only group VI could lyse all six of these strains, and groups I, IV, VII, IX, $\mathrm{X}, \mathrm{XI}$, and XII gave neither inhibition nor lysis with any of the Caulobacter strains tested.

Strains of 54 species of bacteria other than caulobacters were also tested for susceptibility to these phages. None of these organisms showed any susceptibility to the Asticcacaulis phages.

Electron microscopy. All phages in groups I 
through V and VII through IX are similar in appearance, with heads hexagonal in outline and measuring $65 \mathrm{~nm}$ in diameter and with relatively rigid noncontractile tails 160 to 220 $\mathrm{nm}$ in length. Representative phages are shown in Fig. 1 through 4 . These phages are often seen attached to filaments approximately $3 \mathrm{~nm}$ in diameter (Fig. 2 through 4), which is similar to that of pili, but no further evidence has been sought for their site of attachment. Terminal appendages are sometimes seen at the site of attachment.

Phages in group VI have elongated heads 45 $\mathrm{nm}$ in width and 220 to $280 \mathrm{~nm}$ in length and have flexible noncontractile tails 320 to $340 \mathrm{~nm}$ in length (Fig. 5).

Group X phages (Fig. 9) have elliptical heads measuring $65 \mathrm{~nm}$ in diameter (or $50 \mathrm{~nm}$ in uranyl acetate) and 85 to $100 \mathrm{~nm}$ in length with flexible noncontractile tails 260 to $270 \mathrm{~nm}$ in length.

Phage $\phi \mathrm{AcS}_{1}$ (group XI) has a large and elongated head with dimensions of 70 by $260 \mathrm{~nm}$ as visualized with KPT stain. Empty heads vary from 70 to $85 \mathrm{~nm}$ in diameter and range from 260 to $500 \mathrm{~nm}$ in length, nearly double the length of the normal (260-nm) heads (Fig. 7). The head appears more slender when stained with uranyl acetate and gives dimensions of 50 by $260 \mathrm{~nm}$ (Fig. 8). A few double-length empty heads are also seen in uranyl acetate (Fig. 6). The flexible noncontractile tails are $10 \mathrm{~nm}$ in diameter and 280 to $320 \mathrm{~nm}$ long and are sometimes seen attached to filaments approximately $3 \mathrm{~nm}$ in diameter.

Phages in group XII have not yet been observed microscopically.

Phage plaque morphology. All phages in groups I through IX give plaques that are cloudy to some degree and have diffuse edges. Plaques vary in size from pinpoint to $1.5 \mathrm{~mm}$ in diameter (Table 3). Groups X through XII give clear plaques that are characteristically variable in size. Except for $\phi \mathrm{AcJ}_{1}, \mathrm{~S}_{2}$, and $\mathrm{S}_{3}$, all phages in the last three groups have the same plaque morphology. $\phi$ AcJ $_{1}$, after repeated transfers, gave larger plaques 2 to $4 \mathrm{~mm}$ in diameter. $\phi \mathrm{AcS}_{2}$ and $\mathrm{S}_{3}$ gave smaller plaques with sharp edges. Figure 10 shows plaques representative of each morphological type.

Induction. Neither the broth method nor the rapid plate method was successful in inducing any temperate bacteriophages from the seven strains of Asticcacaulis tested. The rapid plate method was successful, though, in inducing a lytic activity, possibly a bacteriocin, that was not transferable by picking from the clear zone with a toothpick. Three induced strains gave this result. Induced AC2 was lytic on AC48; induced AC48 was lytic on S-1 and S-3; and induced AC12 was lytic on S-1, S-3, and AC48. The lytic agent was not characterized further. No phages or lytic activities were seen in uninduced cultures.

Serology. Antiserum neutralization tests showed complete serological nonrelatedness between the $A$. biprosthecum phage $\phi \mathrm{AcM}_{2}$ and any phages in groups I through IX and between $\phi$ Ac38 and any $A$. biprosthecum phages (groups X, XI, and XII). First-order reaction constants are given in Table $4 . \mathrm{K}$ values of less than 1 indicate serological nonrelatedness. Of the $A$. biprosthecum phages (groups X, XI, and $\mathrm{XII}), \phi \mathrm{AcM}_{3}$ is probably equivalent to $\phi \mathrm{AcM}_{2}$, and $\phi \mathrm{AcM}_{4}$ and $\mathrm{M}_{5}$ are probably closely related or equivalent to $\phi \mathrm{AcM}_{2}$. All other phages are unrelated to $\phi \mathrm{AcM}_{2}$. Phages of groups I through IX all appear to be related to $\phi \mathrm{Ac} 38$, but those of groups X through XII appear to be unrelated to $\phi \mathrm{Ac} 38$. Antiserum to phages other than $\phi \mathrm{AcM}_{2}$ or $\phi \mathrm{Ac} 38$ would be needed to further define the relationship between these groups.

Nucleic acid determination. Bradley's acridine orange staining technique (5) was used to determine the type and strandedness of nucleic acid for phages in the first 11 groups. All phages stained with acridine orange gave a bright green color which persisted after treatment with molybdic or tartaric acid, indicating the presence of double-stranded deoxyribonucleic acid (DNA). Group XII phages were not tested for nucleic acid type.

\section{DISCUSSION}

The results of the host range studies have taxonomic implications at the family, genus, and species levels. The Asticcacaulis phages showed an abolute specificity for members of the family Caulobacteraceae and had no effect on any of the 54 other species tested. This supports Poindexter's argument for the taxonomic uniqueness of the family Caulobacteraceae (13) and Schmidt and Stanier's view of caulobacters "as a completely isolated group with respect to host/phage interactions" (14).

However, there is no longer an ". . . absolute specificity between. . . [the genera Asticcacaulis and Caulobacter] with respect to host specificity for bacteriophages," as stated by Schmidt and Stanier (14). They found that none of their Caulobacter phages lysed any strains of Asticcacaulis and that none of their Asticcacaulis phages lysed any Caulobacter strains. Eleven of the Asticcacaulis phages isolated in this study are capable of lysing from one to six 

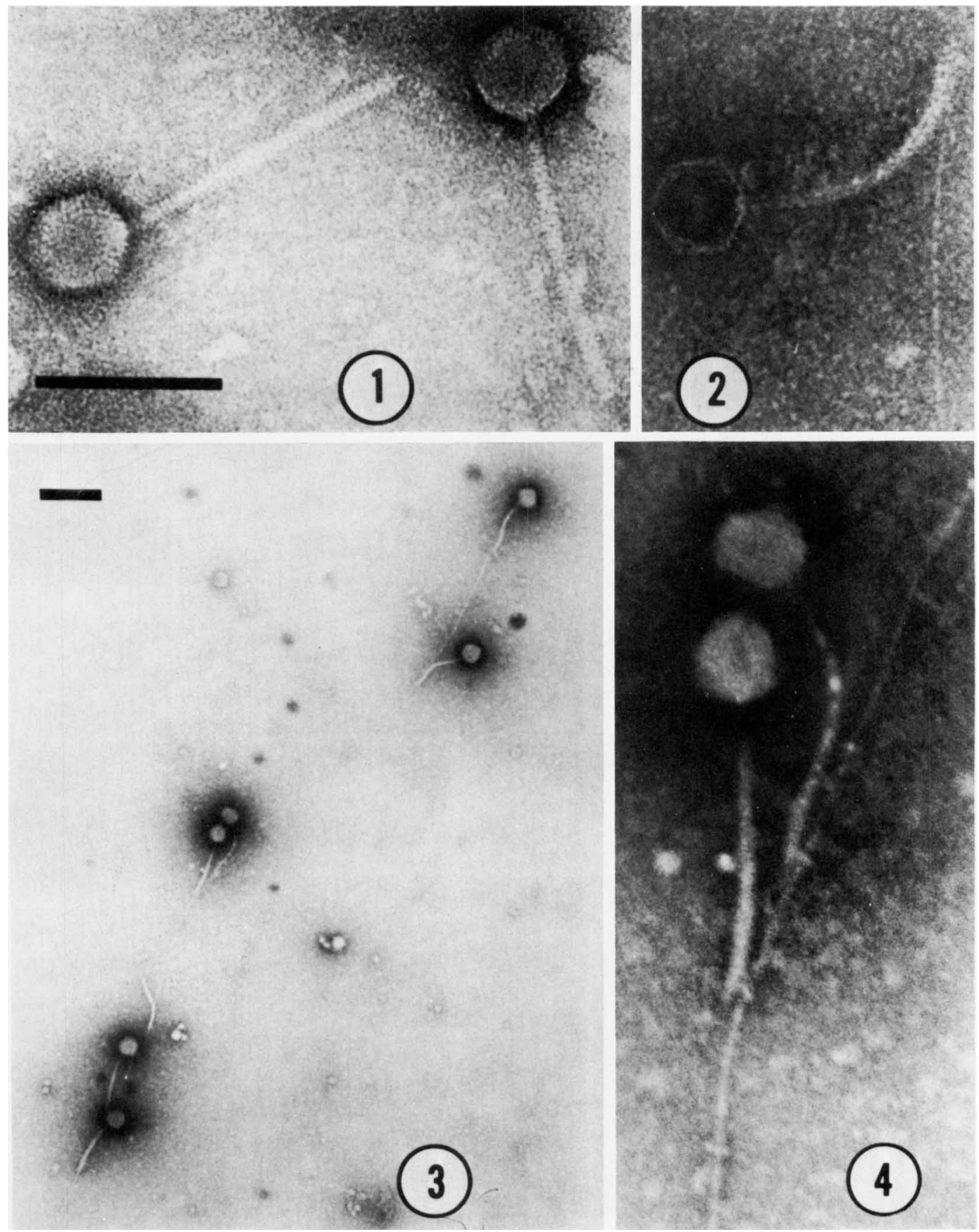

FIG. 1. Phage $\phi A c 31$ stained with uranyl acetate. Head capsomeres and tail striations are apparent. Bar indicates $0.1 \mu \mathrm{m}$.

FIG. 2. Phage $\phi A c 31$ stained with KPT-BSA. Both head and tail have been penetrated by the stain. An electron-transparent ring is evident inside the head. Same magnification as Fig. 1.

FIG. 3. $\phi A c 15$ phages attached to a filament $3 \mathrm{~nm}$ in diameter. KPT-BSA stain. Bar indicates $0.2 \mu \mathrm{m}$.

FIG. 4. Higher magnification of Fig. 3; terminal appendages are apparent. Same magnification as Fig. 1. 

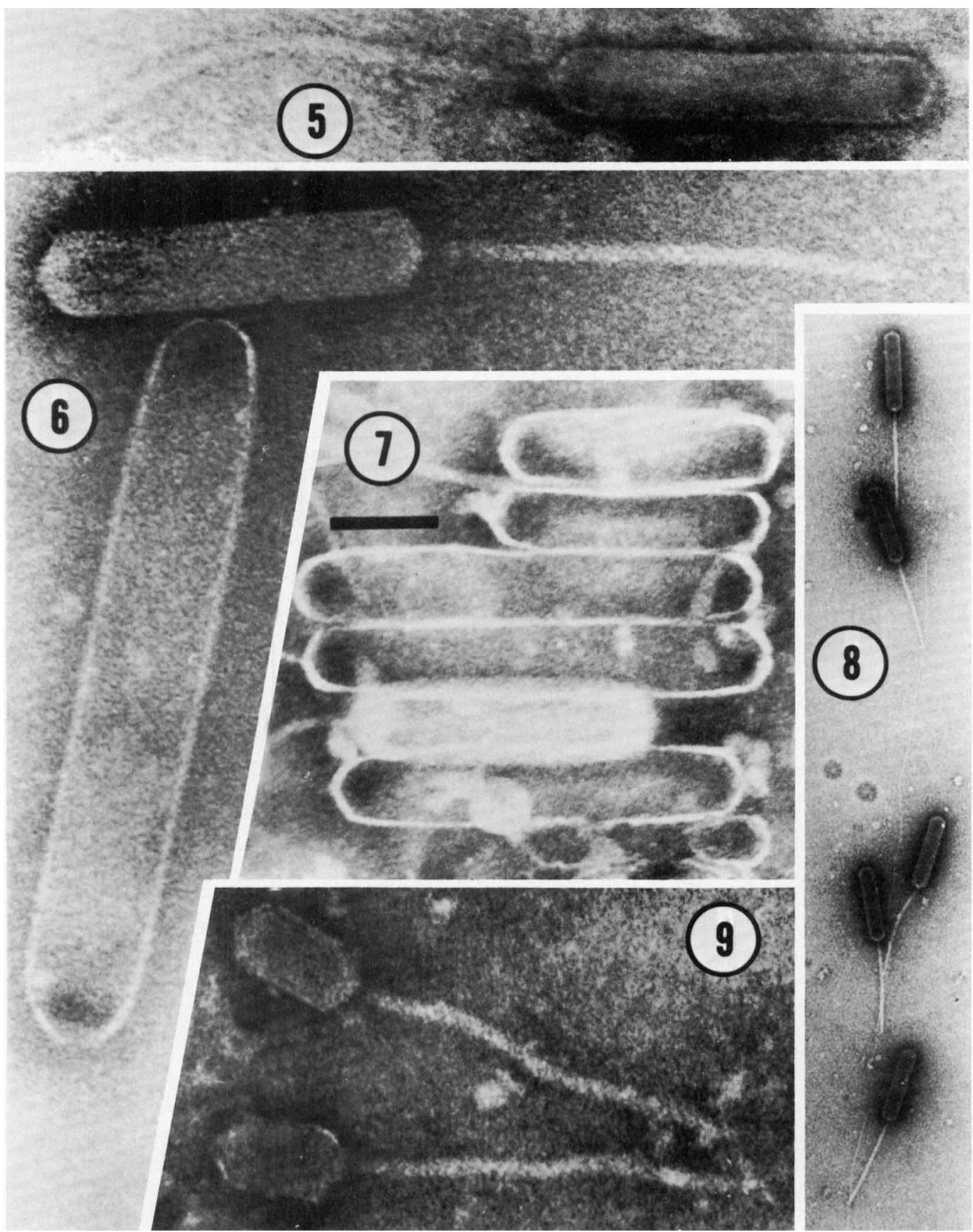

FIG. 5. Phage $\phi A c 41$ stained with uranyl acetate. Same magnification as Fig. 1.

FIG. 6. Phage $\phi A C S_{1}$ stained with uranyl acetate. One head is empty and nearly double the length of the normal $260-\mathrm{nm}$ heads. Same magnification as Fig. 1.

Fig. 7. Phage $\phi A c S_{1}$ stained with $\mathrm{KPT}-\mathrm{BSA}$. Empty capsids of normal $(260 \mathrm{~nm})$ and double $(500 \mathrm{~nm})$ length are present. Bar indicates $0.1 \mu \mathrm{m}$.

Fig. 8. Phage $\phi A c S_{1}$ stained with uranyl acetate. Same magnification as Fig. 3.

Fig. 9. Phage $\phi \mathrm{AcM}_{2}$ stained with uranyl acetate. Same magnification as Fig. 1. 
TABLE 3. Phage plaque sizes and morphologies

\begin{tabular}{lll}
\hline \multicolumn{1}{c}{ Phage group } & Plaque size $(\mathrm{mm})$ & \multicolumn{1}{c}{ Plaque morphology } \\
\hline I and II $(\phi \mathrm{Ac11}, 12,13,14,15)$ & $\sim 1.5$ & Very cloudy, diffuse edge \\
III $(\phi \mathrm{Ac31}, 33,38,39)$ & $\sim 1.0$ & Very cloudy, diffuse edge \\
IV $(\phi \mathrm{Ac35}, 36)$ & $\sim 0.5$ & Cloudy \\
V $(\phi \mathrm{Ac3})$ & $\sim 1.0$ & Somewhat cloudy, diffuse edge \\
VI $(\phi \mathrm{Ac41}, 42)$ & $\sim 1.0$ & Cloudy, diffuse edge \\
VII $(\phi \mathrm{Ac45}, 46)$ & Pinpoint -0.5 & Cloudy \\
VIII and IX $(\phi \mathrm{Ac57}, 59)$ & 0.8 & Cloudy, diffuse edge \\
$\phi \mathrm{AcJ}_{1}$ & $2-4$ & Clear \\
$\phi \mathrm{AcS}_{2}, \mathrm{~S}_{3}$ & Pinpoint -1.0 & Clear, sharp edge \\
$\mathrm{X}, \mathrm{XI}$, and XII (except $\left.\phi \mathrm{AcJ}_{1}, \mathrm{~S}_{2}, \mathrm{~S}_{3}\right)$ & Pinpoint -2.0 & Almost clear \\
\hline
\end{tabular}

TABLE 4. Antiserum neutralization of Asticcacaulis phages

\begin{tabular}{|c|c|c|c|}
\hline \multirow[b]{2}{*}{ Group } & \multirow[b]{2}{*}{ Phage } & \multicolumn{2}{|c|}{$\begin{array}{c}\text { First-order reaction } \\
\text { constants }^{a}\end{array}$} \\
\hline & & $\begin{array}{l}\text { Antise- } \\
\text { rum to } \\
\phi \mathrm{AcM}_{2}\end{array}$ & $\begin{array}{l}\text { Antise- } \\
\text { rum to } \\
\phi A c 38 \\
\end{array}$ \\
\hline \multirow[t]{2}{*}{ I } & $\phi A c 11$ & $<1$ & 5.85 \\
\hline & $\phi A c 14$ & $<1$ & 6.92 \\
\hline \multirow[t]{3}{*}{ II } & $\phi \mathrm{Ac} 12$ & $<1$ & 5.86 \\
\hline & $\phi \mathrm{Ac} 13$ & $<1$ & 7.99 \\
\hline & $\phi \mathrm{Ac} 15$ & $<1$ & 7.18 \\
\hline \multirow[t]{4}{*}{ III } & $\phi A c 31$ & $<1$ & 6.75 \\
\hline & $\phi$ Ac33 & $<1$ & 7.20 \\
\hline & $\phi A c 38$ & $<1$ & 5.91 \\
\hline & $\phi \mathrm{Ac39}$ & $<1$ & 4.30 \\
\hline \multirow[t]{2}{*}{ IV } & $\phi \mathrm{Ac} 35$ & $<1$ & 6.89 \\
\hline & $\phi \mathrm{Ac} 36$ & $<1$ & 6.44 \\
\hline $\mathrm{V}$ & $\phi \operatorname{Ac} 37$ & $<1$ & 6.30 \\
\hline \multirow[t]{2}{*}{ VI } & $\phi \mathrm{Ac} 41$ & $<1$ & 10.46 \\
\hline & $\phi \mathrm{Ac} 42$ & $<1$ & 8.10 \\
\hline \multirow[t]{2}{*}{ VII } & $\phi \mathrm{Ac45}$ & $<1$ & 9.21 \\
\hline & $\phi \mathrm{Ac46}$ & $<1$ & 8.22 \\
\hline VIII & $\phi \operatorname{Ac5} 7$ & $<1$ & 8.51 \\
\hline IX & $\phi A c 59$ & $<1$ & 6.50 \\
\hline \multirow[t]{4}{*}{$\mathrm{X}$} & $\phi \mathrm{AcM}_{2}$ & 1,628 & $<1$ \\
\hline & $\phi \mathrm{AcM}_{3}$ & 1,616 & $<1$ \\
\hline & $\phi \mathrm{AcM}_{4}$ & 651 & $<1$ \\
\hline & $\phi \mathrm{AcM}_{5}$ & 616 & $<1$ \\
\hline XI & $\phi \mathrm{AcS}_{1}$ & $<1$ & $<1$ \\
\hline XII & $\begin{array}{l}\text { Other } \\
\text { C19 } \\
\text { phages }\end{array}$ & $<1$ & $<1$ \\
\hline
\end{tabular}

${ }^{a}$ Per minute.

Caulobacter strains. In addition, Schmidt's strain $\phi$ CFD-1, which is active against at least nine Caulobacter strains, was tested in the present study and found to lyse or inhibit every Asticcacaulis strain used here except AC48.

Host range studies can also indicate relatedness between species and strains of the same genus. In this study, S-1 and S-3 behaved exactly the same, and $\mathrm{C} 19$ and $\mathrm{AC} 2$ showed nearly identical susceptibilities. It was then discovered that the original isolates S-3 and C19 of Pate and Ordal had been redesignated by other workers as $\mathrm{S}-1$ and $\mathrm{AC} 2$, respectively (Schmidt, personal communication). Subculturing produced minimal changes, but otherwise the strains S-1 and S-3 are the same and C19 is the same as AC2.

Similar phage susceptibilities of S-3 and AC48 may indicate a close relationship between the two strains. The inability of $A$. biprosthecum phages to propagate on any other species and the inability of any other phages to propagate on C19 (although Schmidt's $\phi$ CFD-1 and Asticcacaulis phages, as well as 14 of our phages, will inhibit C19) indicate that $A$. biprosthecum is the most genetically isolated of the Asticcacaulis species studied here.

One of the original goals of this work was to find a transducing phage to use as a tool in studying the genetics of Asticcacaulis. Therefore, attempts were made to detect lysogeny in the available strains of Asticcacaulis. No temperate phages were found, and it has not yet been ascertained whether the phages isolated here are capable of transduction. Further work will therefore be required to obtain a viral system for gene transfer.

The phages isolated in this study are all morphologically similar to caulophages isolated elsewhere. Those DNA phages with heads that are hexagonal in outline, such as phage $\phi$ Ac31, are similar to Schmidt's DNA Asticcacaulis phages such as $\phi \operatorname{Ac} 20$ (14) and to Driggers and Schmidt's temperate and defective DNA Caulobacter phages with the noncontractile tails (6). The DNA phages with elongated heads and long tails $\left(\phi A c 41,42\right.$, and $\left.S_{1}\right)$ are similar to known, large DNA caulophages, with $\phi$ Ac41 and 42 most closely resembling Schmidt's 

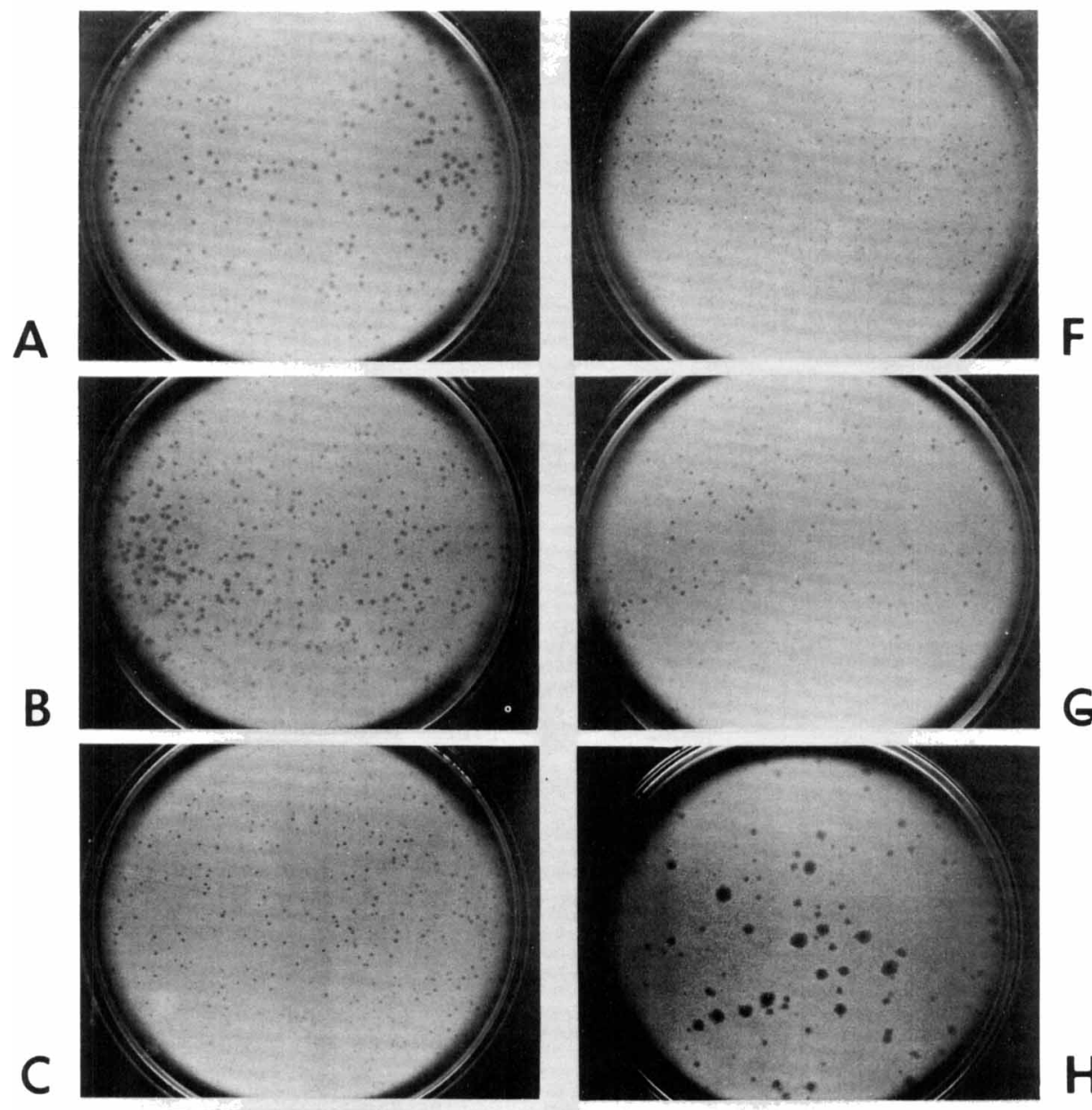

6
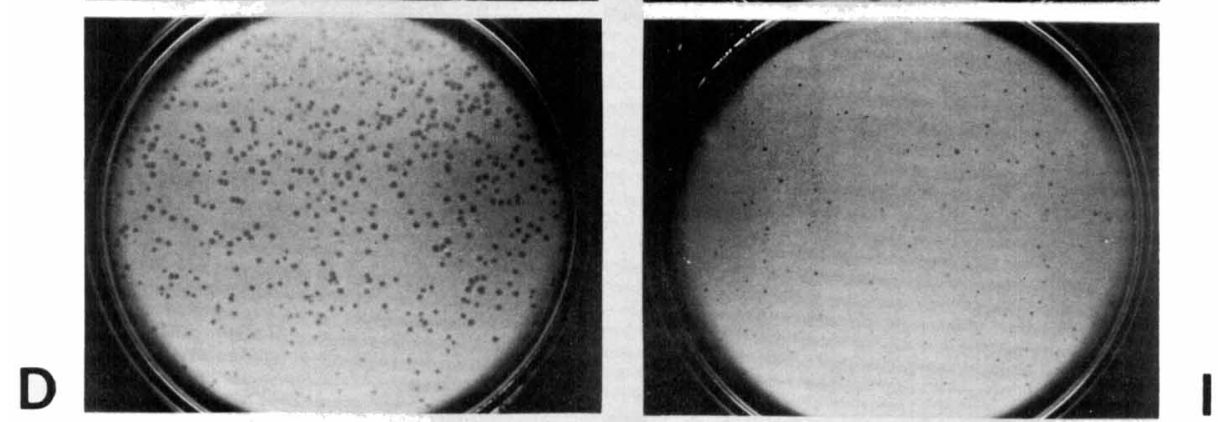

H
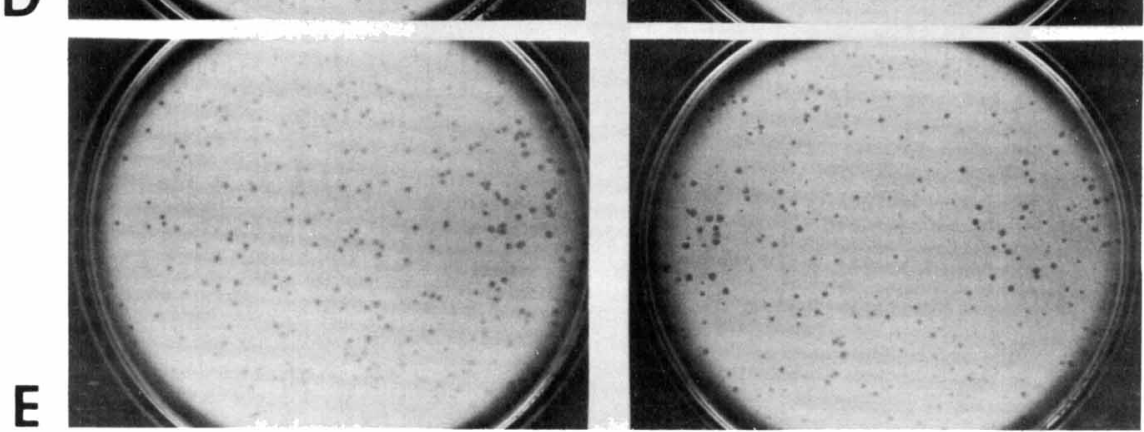

Fig. 10. Typical Asticcacaulis phage plaque morphologies. Magnification, $\times 0.5$. (A) $\phi$ Ac13 plated on Asticcacaulis excentricus AC48. (B) $\phi A c 31$ plated on $A C 48$. (C) $\phi A c 36$ plated on $A C 48$. (D) $\phi A c 37$ plated on $A C 48$. (E) $\phi A C 42$ plated on $A C 48$. (F) $\phi A c 45$ plated on AC48. (G) $\phi A c 57$ plated on AC48. (H) $\phi A C J_{1}$ plated on $A$. biprosthecum $C 19$. (I) $\phi A c S_{2}$ plated on $C 19$. (J) $\phi A c M_{3}$ plated on $C 19$. 
phages $\phi \mathrm{Cb} 3,6$, and 13 (14) and $\phi \mathrm{AcS}_{1}$ most closely resembling Agabian-Keshishian and Shapiro's phage $\phi \mathrm{CbK}$ (2). Phage $\phi \mathrm{AcM}_{2}$ is also similar to the other elongated caulophages, but it has a shorter head. No small spherical phages, such as Schmidt's ribonucleic acid phages $\phi \mathrm{Cb} 8 \mathrm{r}, 12 \mathrm{r}$, or $23 \mathrm{r}$, were seen (14).

\section{ACKNOWLEDGMENTS}

We are very grateful to Jean M. Schmidt of Arizona State University for providing us with 37 caulobacter strains and 3 caulophages.

This research was supported by the College of Agricultural and Life Sciences, University of Wisconsin at Madison, and by Public Health Service grant 1-RO1-GM 19859 from the National Institute of General Medical Sciences.

\section{REPRINT REQUESTS}

Address reprint requests to: Dr. J. L. Pate, Department of Bacteriology, University of Wisconsin, Madison, Wis. 53706 .

\section{LITERATURE CITED}

1. Adams, M. H. 1959. Bacteriophages. Interscience Publishers, Inc., New York.

2. Agabian-Keshishian, N., and L. Shapiro. 1970. Stalked bacteria: properties of deoxyribonucleic acid bacteriophage $\phi \mathrm{CbK}$. J. Virol. 5:795-800.

3. Agabian-Keshishian, N., and L. Shapiro. 1971. Bacterial differentiation and phage infection. Virology 44:46-53.

4. Bradley, D. E. 1962. A study of the negative staining process. J. Gen. Microbiol. 29:503-516.

5. Bradley, D. E. 1966. The fluorescent staining of bacteriophage nucleic acids. J. Gen. Microbiol. 44:383-391.

6. Driggers, L. J., and J. M. Schmidt. 1970. Induction of defective and temperate bacteriophages in Caulobac- ter. J. Gen. Virol. 6:421-427.

7. Henrici, A. T., and D. E. Johnson. 1935. Studies of freshwater bacteria. II. Stalked bacteria, a new order of schizomycetes. J. Bacteriol. 30:61-93.

8. Jollick, J. D. 1972. Differential phage sensitivity of cell types in Caulobacter. J. Gen. Virol. 16:405-407.

9. Jollick, J. D., and E. M. Schervish. 1972. Genetic recombination in Caulobacter. J. Gen. Microbiol. 73:403-407.

10. Kurn, N., S. Ammer, and L. Shapiro. 1974. A pleiotropic mutation affecting expression of polar development events in Caulobacter crescentus. Proc. Natl. Acad. Sci. U.S.A. 71:3157-3161.

11. Leffler, S., M. Hierowski, J. S. Poindexter, and W. Szer. 1971. Large scale isolation of the caulobacter bacteriophage $\phi \mathrm{Cb} 5$ and its RNA genome. FEBS Lett. 19:112-114.

12. Pate, J. L., J. S. Porter, and T. L. Jordan. 1973. Asticcacaulis biprosthecum: life cycle, morphology and cultural characteristics. Antonie van Leeuwenhoek J. Microbiol. Serol. 39:569-583.

13. Poindexter, J. S. 1964. Biological properties and classification of the Caulobacter group. Bacteriol. Rev. 28:231-295.

14. Schmidt, J. M., and R. Y. Stanier. 1965. Isolation and characterization of bacteriophages active against stalked bacteria. J. Gen. Microbiol. 39:95-107.

15. Shapiro, L., and N. Agabian-Keshishian. 1970. A specific assay for differentiation in the stalked bacterium Caulobacter crescentus. Proc. Natl. Acad. Sci. U.S.A. 67:200-203.

16. Shapiro, L., N. Agabian-Keshishian, and I. Bendis. 1971. Bacterial differentiation. Science 173:884-892.

17. Shapiro, L., N. Agabian-Keshishian, A. Hirsch, and $O$. M. Rosen. 1972. Effect of dibutyryl cyclic $3^{\prime}: 5^{\prime}$-AMP on growth and differentiation in Caulobacter crescentus. Proc. Natl. Acad. Sci. U.S.A. 69:1225-1229.

18. Siddiqui, A., E. Hart, U. Mandagere, and I. D. Goldberg. 1974. Rapid plate method for the isolation of lysogenic bacteriophages. Appl. Microbiol. 27:278280 . 